\title{
Development of a Learning School in Wat Srichan School, Khon Kaen Province: A Participatory Action Research
}

\author{
Phramaha Jittipong Chanthago (Phuttakhan) ${ }^{1}$, Phrakrudhammapissamai $^{1}$ \& Chayanon Jantaragaroon ${ }^{1}$ \\ 1 Doctor of Education, Program in Educational Administration, Mahamakut Buddhist University, Isan Campus, \\ Thailand \\ Correspondence: Phrakrudhammapissamai, Doctor of Education, Program in Educational Administration, \\ Mahamakut Buddhist University, Isan Campus, Thailand. E-mail: chaisamai@ hotmail.com
}

Received: September 8, 2019

Accepted: October 19, 2019

Online Published: October 23, 2019

doi:10.5430/ijhe.v9n1p11

URL: https://doi.org/10.5430/ijhe.v9n1p11

\begin{abstract}
This research was conducted in order to develop a learning school system at Wat Srichan School. This monk school has experienced problems related to quality due to the students' low proficiency as evidenced in the unsatisfying O-net Test score. This research was framed around the participatory discipline in which both critical social theory and theory of post-modernism were integrated in order to assure the attainment of information from collobaration between the researcher and the research participants. Thirty research participants were engaged in different processes of the research, including planning, acting, observing, and reflecting upon the results. These research processes were deployed in 2 semesters between the academic year 2015-2016. The development was aimed at creating positive changes in the student's learning. The research created three developmental projects: 1) Creating an environment that promoted learning, 2) Developing teachers to foster teaching skills that promote critical thinking and creativity among the learners, and 3) Developing critical thinking skills and creativity for the learners. The projects were found to be effective for the promotion of learning at the school because the overall scores of all of the projects' indicators and the score for each individual project were both averaged above 3.50. The project helped to create awareness among the researchers and the participants regarding the importance of collaborative and democratic measures as crucial means for success. Particularly in this research, it was observed that in order for the learning environment to be created the three projects mentioned above should be implemented.
\end{abstract}

Keywords: participatory research, learning school, Wat Srichan School

\section{Introduction}

\subsection{Introduce the Problem}

The emergence of soaring social mobilization under the wheel of globalization has triggered a new challenge for the education worldwide with the need to turn schools into learning hubs. The role of schools has been overhauled from direct teaching centers to places where the growth of creativity and multiple disciplines are cultivated among the learners in order to prepare them for the citizenship in the changing world. Particularly under the new dimension of school development, the students should be implanted with life skills to get them ready for their future careers and professions. Sinlarat (2007) postulated that the world society is formulated with mobility and changes that take place in economy, politics, technology, and also in education. People inevitably resort more to knowledge-based decisions because knowledge is used as a means to project the all-encompassing development of a community. Cheng (2013) put that education is a long-term investment to create quality population for the future which is speculated as a lucrative return for a country. Based on this principle, Thailand 4.0 has been used as a blueprint for the development of the country, which is believed to be based on the creation of quality workers with proper technological and digital skills. Equipping the workers with these skills, Thailand is certain to face a bright fortune by escalating its GDP, which has brought Thailand from the middle-income range over the past decades to a country with digitalized industry with higher income. Sak-Worawit (2017) said Thailand needs development in all areas to attain the terminal goals of Thailand 4.0. Thai education and Thai teachers are accordingly in need of development to chorus to the country's optimal goal in making Thailand a new leading nation with smart population in the world (Mali-Suwanon, 2016). 


\subsection{Importance of the Problem}

Wat Srichan School is a Buddhist scripture school of the general education session. Overview, the Buddhist scripture schools of the general education session, the schools which are founded for educating and training the male youths ordained in Buddhism by using the teaching of the Lord Buddha as the main curriculum so that the learners can learn morality, virtue, and ethics as Thailand is the city of Buddhism, have encountered the problems concerned with the continuously unimproved teachers. As a result, the operation is not effective as it should. The Office for National Education standards and Quality Assessment (Public Organization) has proposed, after having assessed, that the teachers must be improved in terms of the proficiency of the teaching and learning management and the extra-curricular activity to encourage the learners to gain the thinking skills and the knowledge seeking skills, including the teacher development for authentic learning assessment, the production and application of technology for teaching all the subjects (Ratchamunee, 2012)

Wat Srichan School is located in Srichan Temple (The Royal Temple), Mueang District, Khon Kaen Province, Thailand. The school availables from pre-primary level (kindergarten) up to the high school level. Information in the academic year 2015 which is the year of research there were 175 kindergarten students, 231 elementary school students, 117 junior high school students, 18 high school students, a total of 541 people. Wat Srichan School had 40 teachers (14 males, 26 females).

Wat Srichan school is the same as other Buddhist scripture schools around the country has experienced problems with quality, such as failing the Educational Standard Assurance as evaluated by the National Office of Educational Standard Assurance. Moreover, the students' academic achievements, as portrayed by the O-net test, were insufficient. The school administrators were well aware of the importance of the school to pursue its motto: "Wat Srichan School is a school that aims to raise its students at standard level, to equip the students with creativity, technological skills, and morale, while it is deemed equally important to create knowledgeable and cooperative staff who value Thai culture under ASEAN community". (Wat Srichan School, 2015)

With awareness of the quality problems of teaching and learning in Wat Srichan School and the realization of the benefits of learning development in schools. The researcher wished to articulate the above policy by making Wat Srichan School a learning hub. This research was based on the participatory action research (PAR) which was referred to by Sanrattana (2018) as a research method that incorporates both the Critical Social Theory and the Theories of Post-modernism into the processes of research implementation. The participatory research method values all of its participants' experiences as a key to its operational success. In addition to participation, a democratic system that allows equality among the participants can lead to the very positive changes that bottom-up development has been founded upon. All the participants are equally involved in all of the research processes: planning, acting, observing, and reflecting. Since all of the participants had been engaged in the work processes in a spiral cycle pattern, there was more sustainable development.

Based on the process of the participatory action research as discussed above, the researcher believed that the method would be able to help create a learning school environment at Wat Srichan School. Participatory action research was observed to be effective in making positive changes at school level due to the fact that its principles engage both the researcher and the research participants in the processes of the development. The method has been effectively used in the development of a digital classroom at Jantawitayakom Ecclesiastical Secondary School (Supakijo, 2016), and in the development of PLC via E-learning: a participatory action research study conducted at Mahamakut Buddhist University Isan Campus (Tacha, 2016).

\subsection{Research Objective}

This research aimed at promoting Wat Srichan School as a learning place via the application of the Participatory Action Research. The research investigated three areas of development: 1) Anticipated and unanticipated changes, 2) Learning at the individual level, the group level, and the school level, and 3) New knowledge obtained from the attempt to a promote learning environment in Wat Srichan School.

\section{Research Methodology}

\subsection{Principles and Concepts}

This research was based on the participatory action research (PAR) according to the viewpoint of Sanrattana (2018) and also Seymour-Rolls \& Hughes (2000) Mills (2007) Quixley (2008) James, Milenkiewicz \& Bucknam (2008) Creswell (2008) McTaggart (2010) indicated that the research method can incorporate both the Critical Social Theory and Theories of Post-modernism into the processes of research implementation. The participatory research method values all of its participants' experiences as a key to its operational success. In addition to participation, a democratic 
system that allows equality among the participants can lead to positive changes, which bottom-up development has been founded upon. All the participants are equally involved in all of the research processes: planning, taking action, observing, and reflecting. Since all of the participants are engaged in the work processes in a spiral cycle pattern, the development is made sustainably. (Note: Due to the limited time availability, the research was conducted at two spatial times, thus taking two semesters to complete.). Based on the participatory action research, the participants' roles were changed from passive to active, which involved them in taking part in the research processes as participants. The research method was additionally changed from having the participants be the subjects of the research (better known as research "on them") to research by them and for them. Moreover, the method also changed the researcher's role from an external expert to leveled research participant. The participatory action research did not only try to simply help the researcher understand the existing circumstance, but it also prescribed the necessary measures to help target the optimal goals and create sustainable changes, resulting from collaboration with all of the research participants.

Implementing the participatory action research took into account the importance of the following ten principles: 1) Particularity of the research context; 2) Plurality of skills; 3) Targeting of changes; 4) Taking action for success, 5) Listening to all people's opinions; 6) Analysing and carrying out self-evaluation; 7) Being aware of the value and expertise of the community stakeholders; 8) Learning from both mistakes and success; 9) Keeping records of the changes at the individual, group, and school levels; and 10) Establishing more sustainable development. The Ten Moral Codes that helped to frame the research were as follows: 1) Keeping information confidential; 2) Enabling equal accessibility to research approach among the participants; 3) Directing the anticipated outcomes via cooperation; 4) Enabling full participation from the research informants; 5) Valuing all opinions and obtaining approval from all stakeholders; 6) Obtaining permission to review documents for other purposes; 7) Making the results available to the public to gain their suggestions; 8) Proclaiming to not violate any copyrights and attitudes proposed by others except after obtaining permission to do so; 9) Showing the research processes, results, suggestions, and benefits to the participants; 10) Acknowledging that all of the research participants had contributed to the research and that their decisions to not cooperate in the research process had been respected. Finally, the following ten roles of the researcher were: 1) Teacher, 2) Leader, 3) Listener, 4) Planner, 5) Designer, 6) Analyst, 7) Synthesizer, 8) Observer, 9) Reporter, and 10) Supporter \& Facilitator.

\subsection{Research Area}

This school level research was conducted at Wat Srichan School, which is located in Srichan Temple (The Royal Temple), Mueang District, Khon Kaen Province, Thailand. This school availables from pre-primary level (kindergarten) up to the high school level. Information in the academic year 2016 which is the year of research there are 175 kindergarten students, 231 elementary school students, 117 junior high school students, 18 high school students, a total of 541 people. Wat Srichan School was selected for this research with the following reasons: The school underwent some quality problems, such as students' obtaining low O-net achievement and the school failing the School Standard Assurance Evaluation by the Office for Educational Standard Assurance. (Wat Srichan School, 2015). It was additionally observed that the teachers at Wat Srichan School lacked the capabilities to be "Modern-age Teachers". They were observed to possess low levels of technology, to have limited teaching methods, and to be unable to perform a part of a team.

\subsection{Research Participants}

In 2015, Wat Srichan School had 40 teachers (14 males, 26 females). From the research result in step 1 which will be discussed below, the researcher took into consideration the ethics of the research article 9 and 10 mentioned above: "...9) The researcher must demonstrate the nature of the research process at the outset including providing information about the research guidelines and benefits that will be received and 10) The research participants have different influences on the work but the part that does not want to participate personal rights". By the research process that takes into consideration the said research ethics, 30 subjects participated voluntarily. These 30 participants were divided into 9 males and 21 females. All have a bachelor's degree in education. Age between 30 45 years old. They all participated in the research until the end.

\subsection{Reseqrch Procedures}

Two research operation periods were allowed during two semesters: between May to September, 2015 (Round 1) and November to April, 2016 (Round 2). The research was based on ten operational steps; the first five steps were carried out during the First Semester and the other five were performed during the Second Semester. The ten research steps were as follows: 
Step 1: Preparing The following were implemented: 1) Becoming familiar and getting to know each other, 2) Empowering the members, 3) Planning, and 4) Concluding the plan. The outcomes from this step were: 1) Obtaining informed consent forms from each of the research participants, and 2) Obtaining the research agenda.

Step 2: Planning The procedures that were implemented in this step were: 1) Brainstorming and becoming aware the problems, 2) Acknowledging the theories and clues related to the practices of creating a learning school, 3) Making an operational plan, and 4) Concluding the task. The outcomes from this phase were as follows: 1) The participants understood the processes that they have to undergo in making their school a learning place. The teacher participants were acknowledged about the following needs: 1) to correctly teach as Teachers of the Modern Age, 2) to use technology and various teaching techniques in the classroom, and 3) do work together as a team. Three projects resulted from this stage as follows: 1) The development of a Learning Environment Project; 2) The teacher development project, which was aimed to equip the teachers with ability to elicit creativity and critical thinking skills of the students; and 3) The Student Development Project to trigger creativity and critical thinking skills.

Step 3: Acting The following practices were implemented at this step: 1) Specifying the techniques and instruments of the research; 2) Specifying measures to be taken by the participants; 3) Evaluating the teaching plan, which was aimed at promoting critical thinking and creativity prior to actually using it for instruction; and 4) Implementing the plan. The following results were obtained at this step: 1) the research participants for each semester were obtained and one person was appointed as the overall Evaluator of the project and 2) the five research instruments were obtained.

Step 4: Observation Activities that were completed at this step were: 1) Observing and recording the results, 2) Presenting the results, and, 3) Drawing conclusions about the results. This stage helped obtain the following outcomes: 1) the researcher and the participants understood the observational techniques and were able to effectively use the observational tool, and 2) the participants understood the project evaluation processes and were able to work together as a team.

Step 5: Reflection The things that were implemented under this stage were: 1) Carrying out the implementation of the plan, and 2) Evaluating and Concluding. The results from this stage were the fact that the participants had witnessed changes in the students' learning and had obtained new pieces of knowledge.

Step 6: Re-planning This stage consisted of the following: 1) Creating incentives, 2) Allocating measures to solve problems, 3) Remaking the plan, and 4) Concluding about the actions that had been taken. This stage helped the researcher to obtain a newly revised plan, which could be used for sustainable development.

Step 7: Re-acting The following were implemented at this step: 1) Specifying the measures to be acted upon, and 2) carrying out the plan, which required all research participants to re-do the tasks, which had previously been done in the First Semester.

Step 8: Re-observing This stage involved the following: 1) Observing and recording of the results, 2) Presenting the results, and 3) Evaluating and implementing the plan. The results from this stage were: 1) The researcher and the participants understood observational techniques and were able to effectively use observational tool, and 2) the participants understood the project evaluation processes and were able to work as a team.

Step 9: Reflecting Again The activities implemented in this phase were: 1) Drawing conclusions about the acting of the revised plan, 2) Evaluating and concluding the re-acting of the plan, and 3) Drawing conclusions. The results from this stage were based on the fact that the participants had witnessed changes in the students' learning and had obtained new knowledge, resulting from the performances at the individual, the group, and the school levels.

Step 10: Drawing the the Overall Conclusions The Overall Conclusions of the projects were based on the application of the participatory action research in establishing a learning environment at Wat Srichan School.

\subsection{Research Instruments and Data Organizing}

The research instruments for data collection in the field were developed based on a framework proposed by Mills (2007). The three instruments were as follows: 1) The in-depth interview form and the focus group interview form; 2) The observation form, which was used for the progress report; and 3) The examination of the records, such as journal and field notes. Data obtained from these 3 types of instruments is data from observation and recording in the field. It is a qualitative data for brainstorming and conclusion in the reflection process.

The research instruments for data collection in order to assess the success of operations compared to the specified criteria was a 5-level questionnaire which is the highest, most, medium, less, and the least. The instrument was developed from the results of a study of the conceptual framework of the learning school from the concepts of 
Sergiovanni (1994); Sergiovanni (1998); Mark (2004); Watsons and Marsick (1993); and Simmons (2012). The content is categorized into 3 areas: learning environment, teachers, and students, in total there are 28 questions. This questionnaire was checked for the index of item-objective congruence (developed by Rovinelli and Hambleton in 1977 cited in Turner \& Carlson (2009) is a procedure used in test development for evaluating content validity at the item development stage) by 3 academic experts and 2 evaluation experts. Then, the questionnaire was tried out with 30 teachers in Prapasssorn Witaya School which is not the school used in the research. Data were analyzed to find the alpha coefficient of reliability by employing Cronbach. The results revealed that the questionnaires contain the alpha coefficient of reliability equal 0.93 which is higher than the specified threshold 0.70 . (Prasertratasin, 2003). The data obtained from this questionnaire is quantitative data, analyzed by computer for arithmetic mean and standard deviation as shown in table 1.

\section{Results}

\subsection{Changes}

The following anticipated and unanticipated outcomes were observed:

\subsubsection{The Anticipated Outcomes}

This research is not experimental research. Therefore do not show the results of the evaluation in a manner comparing the scores before and after the research by t-test, but showing results achieved by comparing the criteria set to get a score of 3.50 or higher from a full score of 5 points. The analysis of the 5 level questionnaire data collected from 30 research participants found that all criteria were achieved as shown in Table 1

Table 1. The result of evaluation of the level of being a learning school of Wat Srichan School

\begin{tabular}{|c|c|c|}
\hline Evaluation list & Mean & S.D. \\
\hline Learning environment & 4.13 & 0.57 \\
\hline $\begin{array}{l}\text { 1. There is a learning management process that focuses on promoting analytical } \\
\text { thinking of students. }\end{array}$ & 4.30 & 0.47 \\
\hline 2. There are activities that focus on promoting the analytical thinking of students. & 4.20 & 0.53 \\
\hline $\begin{array}{l}\text { 3. Students and teachers are integrated in the activities that promote the analytical } \\
\text { thinking of students. }\end{array}$ & 4.20 & 0.49 \\
\hline $\begin{array}{l}\text { 4. There is an urge for students "Enthusiastic learner" and have behavior "Knowledge } \\
\text { Sharing" of the school }\end{array}$ & 4.17 & 0.67 \\
\hline $\begin{array}{l}\text { 5. There are learning activities to improve thinking skills rather than focusing on } \\
\text { learning memory skills. }\end{array}$ & 4.50 & 0.49 \\
\hline $\begin{array}{l}\text { 6. In the classroom, there are activities to give students the opportunity to apply and } \\
\text { apply knowledge in various situations. }\end{array}$ & 4.10 & 0.51 \\
\hline $\begin{array}{l}\text { 7. Provide opportunities for learners to be independent in self-direction and be } \\
\text { responsible for their own learning }\end{array}$ & 4.00 & 0.61 \\
\hline $\begin{array}{l}\text { 8. Use cooperative learning groups and other diverse learning methods, rather than } \\
\text { relying on individualized learning and competing with each other. }\end{array}$ & 4.07 & 0.48 \\
\hline 9. There is a provision of learning that must be linked to many subjects. & 4.03 & 0.62 \\
\hline $\begin{array}{l}\text { 10. Organizing learning experiences in our school, use of resources and learning } \\
\text { resources outside the classroom }\end{array}$ & 4.10 & 0.57 \\
\hline $\begin{array}{l}\text { 11. Using various methods of measurement and evaluation and reasonably appropriate } \\
\text { for assessing student learning and development }\end{array}$ & 4.00 & 0.52 \\
\hline $\begin{array}{l}\text { 12. Allocate time and support professional development for the faculty especially to } \\
\text { improve the curriculum for teaching and learning of students. }\end{array}$ & 4.07 & 0.48 \\
\hline Teacher & 4.10 & 0.65 \\
\hline 13. Knowledge in learning management to develop analytical thinking & 4.25 & 0.51 \\
\hline 14. Skills / techniques in learning management to develop analytica & 4.00 & 0.58 \\
\hline
\end{tabular}




\begin{tabular}{|c|c|c|}
\hline Evaluation list & Mean & S.D. \\
\hline $\begin{array}{l}\text { 15. Able to integrate knowledge / skills / learning management techniques to develop } \\
\text { analytical thinking in learning management in the responsible course }\end{array}$ & 4.10 & 0.52 \\
\hline $\begin{array}{l}\text { 16. The teacher shows shared responsibility for the work or activities carried out at the } \\
\text { school. }\end{array}$ & 4.17 & 0.56 \\
\hline $\begin{array}{l}\text { 17. The teacher demonstrates the principles of exercising power through others rather } \\
\text { than / like giving commands. }\end{array}$ & 4.10 & 0.54 \\
\hline $\begin{array}{l}\text { 18. The use of formal power is based on concepts and principles of professional } \\
\text { knowledge and academic competency. More than sticking to the position and } \\
\text { government regulations }\end{array}$ & 4.17 & 0.52 \\
\hline $\begin{array}{l}\text { 19. The teacher facilitates, gives advice and helps as a mentor for the work done to } \\
\text { improve academic achievement and social life of students }\end{array}$ & 3.95 & 0.43 \\
\hline $\begin{array}{l}\text { 20. The teacher provided social support. To improve academic achievement and social } \\
\text { life of students }\end{array}$ & 3.97 & 0.46 \\
\hline $\begin{array}{l}\text { 21. The teacher demonstrated enthusiasm for learning seriously by giving importance to } \\
\text { the quirky behavior of others in the school. }\end{array}$ & 3.97 & 0.41 \\
\hline $\begin{array}{l}\text { 22. Teachers have created an organizational culture that encourages risk-taking behavior } \\
\text { and encourages the initiation of new methods and methods in schools. }\end{array}$ & 4.30 & 0.44 \\
\hline Student & 4.45 & 0.74 \\
\hline 23. Students have demonstrated themselves as an example of "Life-long Learner" & 4.00 & 0.72 \\
\hline 24. The learners have skills in communication. & 4.70 & 0.80 \\
\hline 25. Students have the ability to think critically. & 4.48 & 0.79 \\
\hline 26. Students have skills in problem solving. & 4.55 & 0.49 \\
\hline 27. The learners have skills, ability in using life skills. & 4.07 & 0.62 \\
\hline 28. Students have skills and abilities in using technology. & 4.43 & 0.58 \\
\hline Total & 4.18 & 0.62 \\
\hline
\end{tabular}

Note: The overall score, rated on these areas prior to the implementation of the project, was 3.05, which was below the speculated average score of 3.50. An average score of 3.07 was observed for the learning environment, 3.04 for the teachers, and 3.03 for the students.

\subsubsection{The Unanticipated Outcomes}

This is a reflection of the qualitative data recorded from observing field operations in various stages. A key finding regarding the changes found in the teachers was their open-mindedness to welcoming new teaching techniques. The key principle for having the teachers make changes here was not ruled out by having teachers, who extensively knew about the teaching techniques. Instead, it was involved with the teachers' levels of awareness and their abilities to bring about change in their learners. The teachers were observed to have applied the teaching techniques for the $21^{\text {st }}$ Century learners which resulted in helping the students to pay better attention during the learning process, while the communities were more engaged in educational management. In addition, the teachers were observed to have performed their duties by utilizing more "new thinking" and being more open to new learning and ideas. This should contribute to the creation of a new working culture in the Wat Srichan School.

\subsection{Learning}

Research results about this "learning from practice" is the result of joint consideration between the researcher and the research participants in the qualitative data recorded from the 3 types of instruments created in the reflection process, concluded as follows. The students realized that by taking part in the discussions, finding solutions for the classroom problems, and by presenting at the front of the class, they had been empowered to better understand the content of the traditional instruction, which was mostly based on lectures. The researchers believed that in order for the school to be overhauled into a more efficient place for learning, it was important to integrate ideas from all people and to use those ideas as a framework for the school development. For this reason, it was important for the researchers to start with a clear mindset when it comes to school development - to the extent that all ideas are 
valuable and that all participants count. The research participants learned the importance of adopting a new teaching style and came to the realization that their conventional ways of teachings had, at best, caused the students to reject learning due to boredom that accompanies those old techniques. Accordingly, technology was valued by the teachers as a tool to elicit more learning and prepare the students to become $21^{\text {st }}$ century citizens, who could gain the capacity to think critically and solve problems. Wat Srichan School learned that the application of the Participatory Action Research had been effective in involving all school stakeholders in making the necessary transitions at the school in order to transform it into an effective place for learning.

\subsection{New Knowledge}

Coghlan and Brannick (2007) and James, Milenkiewcz and Bucknam (2008) stated that, “...despite its limited reference and publication, the ideas of participatory action research are applicable for different contexts to generate similar pattern of results...". This quotation shows that the method can be used to trigger new knowledge within a particular context. Accordingly, the knowledge, which was attained from the application of this participatory method in establishing learning place in Wat Srichan School, is unique. However, it can be applied for use in other contexts to yield similar results when the following five measures are implemented:

3.3.1 The development should set both anticipated and unanticipated outcomes, which should take place in the individual, the group, and the school categories.

3.3.2 The implementation should be set at two phases, with each designated for one semester. The development should include ten steps, which are designated to two phases: Phase 1 involved Steps 1-5: 1) Preparation, 2) Planning, 3) Acting, 4) Observing, and 5) Reflecting. Phase 2 involved Steps 6-10: 6) Re-Planning, 7) Re-Acting, 8) Re-Observing, 9) Reflecting Again, and 10) Drawing Conclusions.

3.3.3 The participants should take part in the creation of the three development projects: 1) The Learning Environment Development Project, 2) The Project for the Development of Teachers' Instructions to promote students' critical thinking and creativity, and 3) The Students' Creativity and Critical Thinking Development Project.

3.3.4 The development should be based on the Principle of Collaboration in which all research participants are equally involved in all processes of the research (i.e., planning, acting, observing, and reflecting of the results). Since the development is based upon collaboration with all stakeholders, the development is performed in a form called the "Spiral Cycle", which results in endless and sustainable development.

3.3.5 The development project should be conducted to challenge the belief in a pitfall that claims the implausibility for the theory to be put to work by instead believing that the principle is useless without being put to work. Therefore, it is crucial for the researchers to scrutinize the literature related to the development of a learning organization in order to ensure that the researcher is theoretically sensitive enough to be applied to the learning of knowledge and to be placed into the planning of their projects. In particular, there is the idea of two steams. The first refers to the academic expertise of the researchers and the other refers to the participants' valuable experiences. These can be merged to empower all parties, who are involved in the establishment of the learning organization in a school system.

To illustrate the ideas of the five measures exercised in this current research, the researcher proposed a Prototype Model for the Development of Learing Organization at the Wat Srichan School in Khon Kaen Province, Thailand which is presented in Figure 1. 


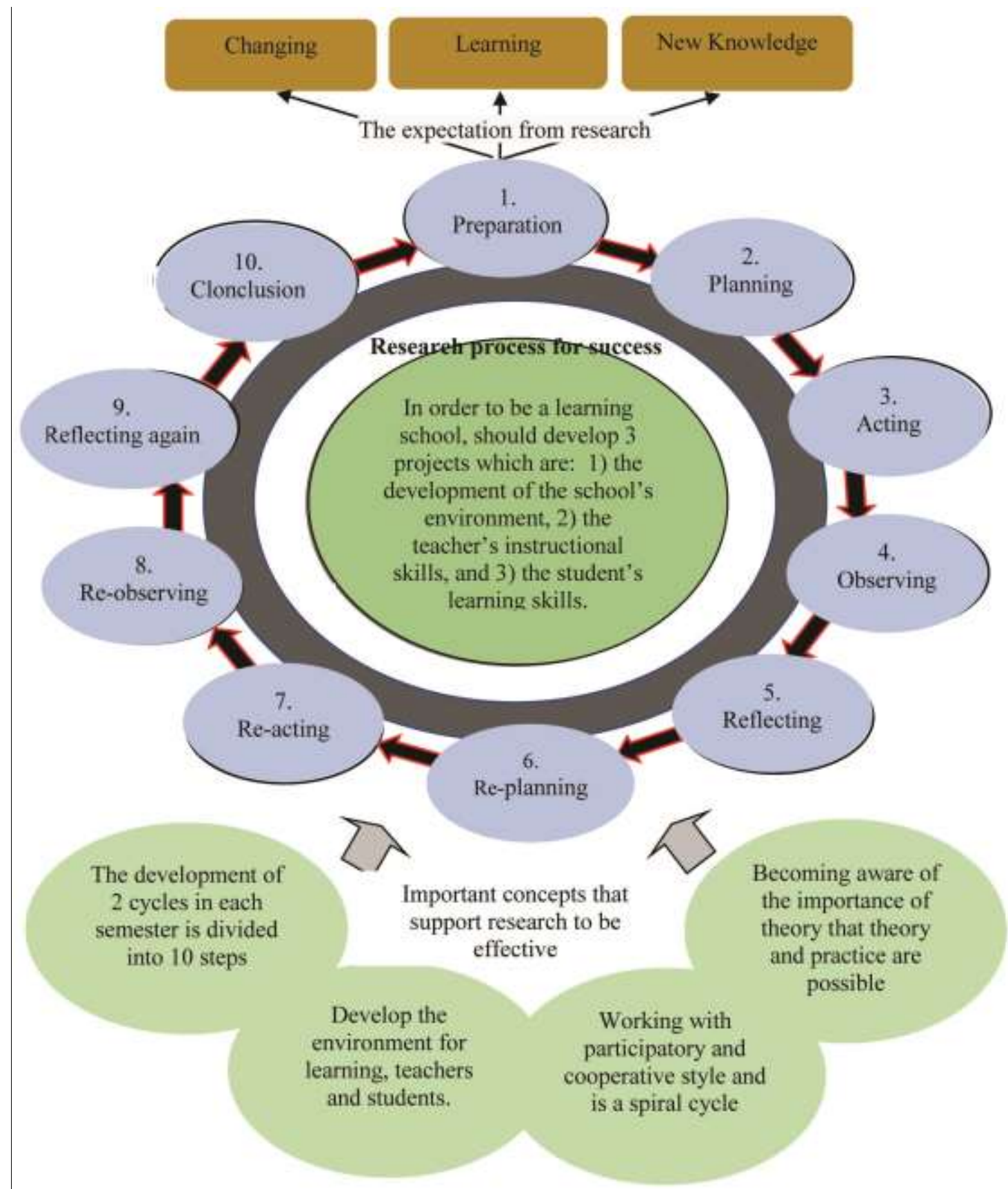

Figure 1. The Prototype Model for the Development of Learing Organization at Wat Srichan School in Khon Kaen Province, Thailand

\section{Discussion and Reccomendations}

\subsection{Changes}

From the research found that the overall score, rated on these areas prior to the implementation of the projects, was 3.05, which was below the speculated average score of 3.50. An average score of 3.07 was observed for the learning environment, 3.04 for the teachers, and 3.03 for the students. But the results of the evaluation after the implementation of the specified projects found that the overall average score was 4.18, when classified in each aspect, it was found that in the aspect of learning environment, there was an average score of 4.13 , the expression of the teachers had an average score of 4.10, and the expression of the students had an average score of 4.45 , all of which was averaged above the criteria set 3.50. The result of the research shows that the research work to develop Wat Srichan School to be a learning school has achieved the research objectives. The reason for this successful research it 
may be because in conducting this research, the emphasis on factors that affect work success are equal participation, awakening self-leadership, the empowerment of theoretical knowledge that the researcher presented to the research participants, performance observation at every stage, and using the results of the recorded observations to brainstorm to reflect the performance. These factors are based on the viewpoint of scholars' views on participatory action research, such as Seymour-Rolls \& Hughes (2000); Mills (2007); Quixley (2008); James, Milenkiewicz \& Bucknam (2008); Creswell (2008); McTaggart (2010) and Sanrattana (2018), and scholars on learning development, such as Sergiovanni (1994); Sergiovanni (1998); Mark (2004); Watsons and Marsick (1993); and Simmons (2012) which is the viewpoint that the researcher has held throughout the period of this research. This result confirms the importance of using the principles and concepts of participatory action research and learning development that can be used successfully.

For the unanticipated outcomes, it was observed that the teachers were able to apply different teaching techniques and became out-of-the-box thinkers. The teachers were more adaptive to the application of new teahcing ideas and willing to learn about new things. This finding was also articulated in Phakphasiviwat (2015) on the extent that the development of human thinking was significantly related to the increasing competition capability. People may need to promptly adjust their mindset to cope with the changing world. Being able to stay attuned to the changing circumstance was believed to be the completed answers for all matters. Sornpang and Saengphan (2017) said that in order to create autonomous learing among their students, it was important for the teachers to put on the students' shoes to really understand how the problems were percepted via the learners' point of views. Then the teachers should elaborate guided questions to lead the students to where they needed to stand to be able to solve the problems by themselves. The results of this research show that teachers have their own potential as a former scholarship if stimulated, promoted, and empowered by academic knowledge will be able to fully demonstrate its hidden potential which resulted in a powerful development based on the concepts of Critical Social Theory and Theories of Post-modernism. (Levinson and Anderson-Levitt, 2015; Duignan, 2019). Therefore, the development of the organization should pay attention to the use of the potential that is embedded in the human body to maximize the benefits.

\subsection{Learning}

From the results of the research mentioned above, both researcher, students, research participants, and schools have learned from practice in many ways. It is learning about new things to do that are different from what they have practiced in the past. It is learning from experiences that result in creativity, trial and error, accepting mistakes for corrective corrections, and thinking outside the box. This phenomenon demonstrates the influence of work or study based on John Dewey's Learning by Doing Theory that says "Experiential learning builds success skills. Extended challenges build project management and collaboration skills as well as initiative and persistence ". (Ark, 2018). Including the influence of active learning, which is a method of learning that encourages creativity, teach people to think, act, and be able to effectively solve problems by themselves, as Anderson, Mitchell, and Osgood 's view say of the importance of active learning: "Increased content knowledge, critical thinking and problem-solving abilities, and positive attitudes towards learning in comparison to traditional lecture-based delivery" (Anderson, Mitchell, and Osgood, 2006). It is also influenced by the development of a learning organization. According to Blackwood (2014), which describes the benefits of developing a learning organization, "Enhanced ability for individuals and teams to embrace and adapt to change." In the end, it is influenced by participatory action research, as Allen (2016) says, "Participatory Action Research is emerging as a useful approach to improving the way we learn about and improve the way we manage these processes".

Since Participatory action research is emerging as a useful approach to improving the way we learn about and improve the way we manage these processes. Therefore, the suggestion from the discussion of this research is to encourage any development by participatory action research, as Allen (2016) mention the benefits of Participatory action research, "The processes that the researcher uses to guide those involved can be seen as iterative learning cycles consisting of phases of planning, acting, observing and reflecting. Fundamental, then, to action research is the concept of "learning by doing". It recognizes that people learn through the active adaptation of their existing knowledge in response to their experiences with other people and their environment."

\subsection{New Knowledge}

The new knowledge, which was developed in this research, is called, "The Prototype Model for the Development of Learning Organization in the Wat Srichan School in Khon Kaen Province". It is a form of knowledge that is particular to the context of the Wat Srichan School. The factors, which are included in the findings of this research, were found to be beneficial for making positive changes to the learning environment at the Wat Srichan School. 
Despite the limitations, which were related to the generalization of this research, in finding another wider context, this research should set an example for other schools and should be able to be applied to them by sharing similar contexts, which were used at the Wat Srichan School. Similar ideas on the application of the research findings from action research were stated by Coghlan et al. (2007) and by James et al. (2008), who commented on the fact that action research may have limitations on the broader spectrum of generalization. Yet, it is able to provide an adequate example for schools having similar contexts and is able to generate similar patterns to assist in making changes to those schools. Similarly, new knowledge was also acquired from a research study examining the application of holistic management in the development of pre-school education at the Dongpong Young Children's Development Center in the Sila Sub-district of Khon Kaen Province (Monpianchan, 2011).

Based on the success of the application of a Participatory Action Research study in the establishment of a school learning environment in the Wat Srichan School, The Prototype Model for the Development of a Learning Organization in the Wat Srichan School in Khon Kaen Province should be used as a model for the continual development of other schools that share similar backgrounds with Wat Srichan School. More developmental aspects can be added to make the model more accommodating to the context of a new target school. The most irrevocable teaching problem centers upon the teachers' refusal to turn away from the conventional method of a teacher-centered style. Therefore, it then becomes important for the teacher or teachers, who are producing the units, to assist in developing teachers, whose capabilities can be well-rounded and who can develop the ability to conduct learning processes under the conditions of contextual changes. Teachers should be trained to conduct integrated instruction and to develop school-based curricula that are appropriate for the particular setting of each school.

\section{References}

Allen, W. (2016). Participatory action research provides for multiple benefits. Retrieved October 18, 2019, from https://learningforsustainability.net/post/par/

Anderson, W.L., Mitchell, S.M. \& Osgood, M.P. (2006). Comparison of student performance in cooperative learning and traditional lecture - based biochemistry classes. Retrieved October 18, 2019, from https://bit.ly/2P33wLc

Ark, T.V. (2018). Learning by doing: 6 Benefits of experiential learning. Retrieved October 18, 2019, from https://bit.ly/33KBjgs

Blackwood, K. (2014). Benefits of creating an organizational learning culture. Retrieved October 18, 2019, from https://bit.ly/2BrNL8F

Cheng, T.U. (2013). (2556). Teacher in the 21st century is a turning point for cross-border education. Retrieved August 9, 2018, from https://bit.ly/2MQnwNB

Coghlan, D. \& Brannick, T. (2007). Doing action research in your own organization. (2nd ed.) Thousand Oaks, CA: Sage.

Creswell, J.W. (2004). (2008). Educational research: Planning, conducting \& evaluating quantitative and qualitative research. 3rd ed. New Jersey: Merrill Prentice Hall.

Duignan, B. (2019). Theories of post-modernism. Retrieved October, 17, 2019, from https://bit.ly/2sr2Tk8

James, E., A., Milenkiewicz, M.T. \& Bucknam, A. (2008). Participatory action research for educational leadership: Using data-driven decision making to improve schools. Thousand Oaks, CA: Sage.

James, E.A., Milenkiewicz, M.T. \& Bucknam, A. (2008). Participatory action research for educational leadership: Using data-driven decision making to improve schools. Thousand Oaks, CA: Sage.

Levinson, B.A. \& Anderson-Levitt, K. (2015). Critical social theory. Retrieved October, 17, 2019, from https://bit.ly/2qj6SPN

Mali-Suwanon, S. (2016). Reducing the disparity in rural education with digital leaps to Thailand 4.0. Retrieved December 24, 2016, from https://bit.ly/2IhQu5C.

Mark K.S (2004). The Theory and rhetoric of the learning society. Retrieved June 23, 2015, from http://www.infed.org.lifeonglearning/b-lrnsoc.htm.

McTaggart, R. (2010). Participatory action research or change and development. Townsville, Australia: James Cook University.

Mills, G. E. (2007). Action research: A Guide for the teacher researcher. (3nd ed.) New Jersey: Merrill Prentice Hall. 
Monpianchan, C. (2011). Early childhood education management: A Case of Dong Phong Child Development Center, Sila Subdistrict Administration Organization, Khon Kaen. Ph.D. Dissertation in Educational Administration Program, Graduate School, Khon Kaen University.

Phakphasiviwat, S. (2015). "Dr. Somchai" pointed out, the world regression has changed, Thailand must adjust. Retrieved June 10, 2018, from https://bit.ly/2o5qkhT

Prasertratasin, S. (2003) Research methodology in social science. Bangkok: Puengfa Printing.

Quixley, S. (2008). Participatory action research: A Brief outline of the concept. Taskforce: Canberra.

Ratchamunee, P. (2012). Progress on education of general Buddhist scripture schools. Retrieved October 15, 2018, from https://bit.ly/2NODv2a

Sak-Worawit, A. (2017). 11 Characteristics of Thai 4.0 that need reform, will help Thailand 4.0 to become a reality. Retrieved March 22ม 2017, from https://bit.ly/2lWEOjA

Sanrattana, W. (2018). Research in educational administration: Concepts and practices. (4th ed.) Bangkok: Thipwisut.

Sergiovanni, T. J. (1994). Building community in schools. San Francisco, CA: Jossey Bass Publishers.

Sergiovanni, T. J. (1998). Leadership as pedagogy, capital development and school effectiveness. International Journal of Leadership in Education, 1(1), 37.

Seymour-Rolls, K. \& Hughes, L. (2000). Participatory action research: Getting job done. Retrieve June 10,2010 from http://www2.fhs.usyd.edu.au/arow/o/m01/

Simmons, C. (2012). Teacher skills for the 21st Century. Retrieved December 5, 2015, from https://bit.ly/2MtaTdl.

Sinlarat, P. (2007). The transition from education into the knowledge economy. Bangkok: Chulalongkorn University.

Sornpang, J. \& Saengphan, J. (2017). The role of teachers in promoting the ability to solve geometric problems of students in the classroom taught by open methods. Journal of Education, Naresuan University, 19(4), 65-77.

Supakijo, S. (2016). The development of suitable digital classroom for Phra Pariyapattham Chanthawitthayakhom School, General Education Department: Participatory Action Research. Ph.D. Dissertation in Educational Administration Program, Graduate School, Mahamakut Buddhist University.

Tacha, W. (2016). E-Learning development for professional learning community: A Case of participatory action research at Mahamakut Buddhist University Northeastern Campus. Ph.D. Dissertation in Educational Administration Program, Graduate School, Mahamakut Buddhist University.

Turner, R.C. \& Carlson, L. (2009). Indexes of item-objective congruence for multidimensional items. Retrieved October 18, 2019, https://bit.ly/2J2tsD1

Wat Srichan School. (2015). Wat Srichan School's information.. Retrieved May 20, 2014, from http://srichanschool.com/mainpage

Watsons, K. E. \& Marsick, V. J. (1993). Sculpting the learning organization. San Francisco: Jossey-Bass. 